\title{
Numerical analysis of clamping pressure during carton clamp handling of heavyweight corrugated packages
}

\author{
Jongmin Park ${ }^{1}$, Jongsoon Kim ${ }^{1}$, Jonghun Park², Laszlo Horvath², Ghiseok Kim \\ (1. Department of Bio-industrial Machinery Engineering, Pusan National University, Miryang 627-706, Republic of Korea; \\ 2. Department of Sustainable Biomaterials, Virginia Polytechnic Institute and State University, Blacksburg, VA 24061, USA; \\ 3. Department of Biosystems and Biomaterials Science and Engineering, Seoul National University, Seoul 151-921, Republic of Korea)
}

\begin{abstract}
In order to determine the theoretical minimum clamping pressure required in carton clamp handling of heavyweight corrugated package (HCP) such as large packages or unitized agricultural product packages, a numerical model of clamping pressure was developed. To develop the model, the dynamic load factor was measured at the handling test course which was designed on the basis of actual handling environment of the target HCP. Also, the static-frictional coefficients between the HCPs and between the HCP and a rubber contact pad of carton clamp arm were analyzed. The main factors in the developed numerical model of clamping pressure were the handling load weight and the effective contact area of the carton clamp arm. In addition, field tests were performed to validate the theoretical minimum clamping pressure calculated from the model. Averaged slip distance from the single package and two packages handling was estimated as a $3.2 \mathrm{~mm}$ through field test, and it is expected that the $3.2 \mathrm{~mm}$ slip distance will be acceptable for a safe operation in the handling environment. The suggested analytical approach with the numerical model can be a useful means for estimating the clamping pressure of the carton clamps used to handle the HCP.
\end{abstract}

Keywords: corrugated paperboard, heavyweight package, agricultural product packages, carton clamp, clamping pressure, dynamic load factor

DOI: $10.25165 /$ j.ijabe.20171005.2917

Citation: Park J, Kim J, Park J, Horvath L, Kim G. Numerical analysis of clamping pressure during carton clamp handling of heavyweight corrugated packages. Int J Agric \& Biol Eng, 2017; 10(5): 25-34.

\section{Introduction}

Transport packaging is increasingly considered to be a critical component to promote the efficiency of the entire logistics process such as transport, inventory,

Received date: 2017-01-07 Accepted date: 2017-06-12

Biographies: Jongmin Park, PhD, Professor, research interests: food processing machinery and system, physical distribution and packaging, Email: parkjssy@pusan.ac.kr; Jongsoon Kim, PhD, Associate Professor, research interests: bio-product safety engineering, Email: jongsoon-kim@pusan.ac.kr; Jonghun Park, $\mathrm{PhD}$, Graduate Research Assistant, research interests: transport packaging design engineering, Email: jonghun3@vt.edu; Laszlo Horvath, PhD, Assistant Professor, research interests: packaging design engineering, Email: lhorvat@vt.edu.

*Corresponding author: Ghiseok Kim, PhD, Assistant Professor, research interests: agricultural engineering, postharvest process engineering, Rm 2218, Bldg 200, 1 Gwanak-ro, Gwanak-gu, Seoul 08826, South Korea. Email: ghiseok@snu.ac.kr. warehousing and communication ${ }^{[1-3]}$. The primary function of transport packaging is to protect products against various physical hazards such as vibration, shock, and compression. The transport packaging can be importantly considered to reduce the loss of agricultural products during the transport process ${ }^{[4-6]}$. In addition, it needs to efficiently interact with materials handling environment during the logistics process ${ }^{[7,8]}$.

Carton clamp is a forklift attachment that carries and lifts up loads such as large packages or unitized agricultural product packages by applying lateral pressure to both sides of the loads. The main advantage of carton clamp is pallet-less loads handling. That is, it enables the handling of various loads, such as home appliances and packaged food or agricultural products without the need for a pallet or skid ${ }^{[9,10]}$. However, carton clamp has limitations when considered from a holistic 
logistics/operation perspective ${ }^{[11-13]}$. Occasionally, it is difficult for carton clamp to work for some stages during the loading/unloading, transport and storage process, even though the carton clamp is useful for handling products during manufacturing and warehousing. Nonetheless, the applications of carton clamp in agriculture are increasingly needed for the enhancement of agricultural product handling efficiency, cost reduction and quality control within several agricultural facilities such as agricultural products wholesale markets or agricultural products processing center. Many researches about the carton clamp have recently been accelerated in order to reduce the use of pallets, since there are increasing logistics costs due to the agricultural requirements for phytosanitary treatment of wooden pallets.

Spencer et al. ${ }^{[12]}$ reported that a minimum horizontal spacing of 7.62-10.2 cm between unit loads is required to accommodate the physical dimensions of the carton clamp. They also mentioned that this disadvantage in space efficiency restricts transformation from typical pallet-based handling to pallet-less load handling by the carton clamp. Singh et al. ${ }^{[13]}$ stated that multi-stacking of the pallet-based unit loads had some vertical spacing for each pallet, while the carton clamp method required some horizontal spacing per loads, and showed that the two handling methods are not significantly different for truck and warehousing stacking in terms of their space efficiency. They also analyzed the effects of the ride height, measuring position and stacking patterns (column and cross) of unit loads on shock intensity, load retention and load containment of unit loads in the carton clamp truck-handling environment using two handling test protocols of ASTM D $6055^{[14]}$ and ISTA $3 \mathrm{~B}^{[15]}$, and demonstrated that there was no significant correlation between stacking patterns for the shock intensity according to obstacle course, ride height, measuring position and drivers. Peter ${ }^{[16]}$ focused on the clamping structure itself and the forces required to handle a paper roll without causing physical damages on it.

Stewart et al. ${ }^{[17]}$ showed that four critical factors significantly influencing the clamping force are handling weight, friction of the contact pad surface, environmental conditions and dynamic load force. They made a Power
Spectra Density (PSD) profile by measuring the vibrations that occur during warehouse handling and truck loading, and then they designed a clamping-force simulation device using the PSD profile to reproduce the handling environment and its associated required clamping force. Although the device successfully simulated the vibration environment for warehouse handling conditions, it could not completely reproduce the vibration condition for the truck-loading environment because of the shock duration pulse that occurred during the truck-loading process.

In carton clamp handling, the most significant factor is commonly considered as the optimum amount of clamping force required to securely handle loads. The clamping force generates the friction required to lift loads up. Therefore, it is strongly associated with the frictional characteristics between the contact pad surfaces of the clamp arm and the loads. The packaged product can be damaged if the clamping force significantly exceeds the minimum clamping force, and the loads cannot be lifted up securely or they may be dropped during handling if the clamping force is substantially less than the minimum clamping force.

In case of $\mathrm{HCP}$ such as refrigerator packages, there are some limitations to our ability to accurately simulate carton clamp handling using the previous test protocols such as ASTM D 6055 $5^{[14]}$ and ISTA $3 \mathrm{~B}^{[15]}$ because these protocols do not consider shocks occurred by the height difference between trucks (trailers) and loading docks during loading and unloading operation. In addition, they do not reflect the sudden stopping of the clamping arm after lifting heavy loads vertically and the lateral force to the load generated by the turning of the clamp truck.

Usually, when the products are handled by carton clamp, the information about carton clamp handling is provided by manufacturers. Some manufacturers specify the clamping force and clamping position on their packaging labels for safe carton clamp handling, while others specify the clamping pressure instead of the clamping force. Variations in information regarding proper carton clamp handling can mislead worker's mistake and damages on the packaged products. 
Namely, the specified clamping force or pressure can either exceed or fall short of the proper clamping force or pressure depending on the size of the clamp arm and the contact area between the clamp arm and the loads.

The goal of this study was to develop a numerical model for determining the clamping pressure during the carton clamp handling of $\mathrm{HCP}$, and to evaluate the numerical model by performing field test. Specific research objectives were as follows:

1) To measure the dynamic load factor for each handling method by using a handling test course designed by the actual warehouse handling and shipping environment for the target HCP (heavyweight refrigerator corrugated package).

2) To analyze the static-frictional coefficients both between the corrugated packages and between the corrugated package and the contact pads of the carton clamp arm.

3) To develop a numerical model to calculate the theoretical minimum clamping pressure required for carton clamp handling of HCP using the dynamic load factor and static-frictional coefficients.

4) To validate the suggested model through field test.

\section{Materials and methods}

\subsection{Static-frictional coefficients}

The static-frictional coefficients between the outer liners of the corrugated paperboard and between the outer liner and a rubber contact pad of the carton clamp arm were measured. Both the machine direction (MD) and cross-machine direction (CD) of the outer liners were used as sample materials, and these samples are separated with three different materials which are commonly used in South Korea as the outer liners of corrugated paperboard. As shown in Table 1, they are KA180 $[25 \%$ Unbleached Kraft Pulp (UKP) $+10 \%$ American Recycled Corrugated Container (ARCC) $+65 \%$ Korean Recycled Corrugated Container (KRCC)] and KLB175 $[40 \% \mathrm{UKP}+30 \%$ ARCC $+30 \% \mathrm{KRCC}]$ and $\mathrm{SC} 220$ $[20 \% \mathrm{UKP}+80 \% \mathrm{KRCC}]^{[18]}$.

An experimental device used to measure the static-frictional coefficients consist of an upper plate containing the rubber contact pad or an outer liner, a lower plate containing a second outer liner, $294 \mathrm{~N}$ of dead weight and an Universal Testing Machine (KST-1000U, KST Inc., South Korea) as shown in Figure 1a. Acrylonitrile Butadiene Rubber material which is commonly used as the rubber contact pad of carton clamp arm was used as test sample in this study. As shown in Figure $1 b$, the rubber contact pad of carton clamp arm has a trapezoid-shaped corrugated surface with a density of $1.24 \mathrm{~g} / \mathrm{cm}^{3}$, tensile strength of $16.6 \mathrm{~N} / \mathrm{mm}^{2}$, and $383 \%$ of elongation at the tear.

Table 1 Material properties of outer liners of corrugated paperboard used in the study

\begin{tabular}{cccc}
\hline Outer liners & Thickness/mm & Ring crush/N & Bursting strength $/ \mathrm{kPa}$ \\
\hline KA180 & $0.21(0.01)$ & $206(12.65)$ & $402.21(24.52)$ \\
KLB175 & $0.22(0.01)$ & $245(10.50)$ & $814.23(35.32)$ \\
SC220 & $0.28(0.01)$ & $260(12.41)$ & $557.54(26.07)$ \\
\hline
\end{tabular}

Note: The values in parentheses are standard deviation.

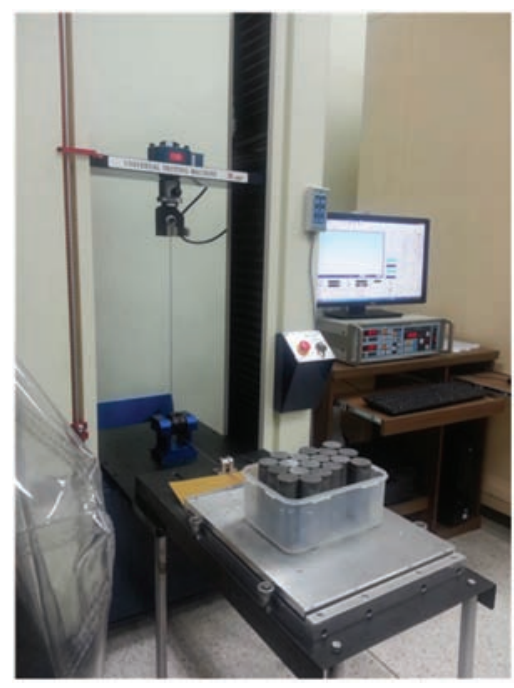

a. Experimental setup

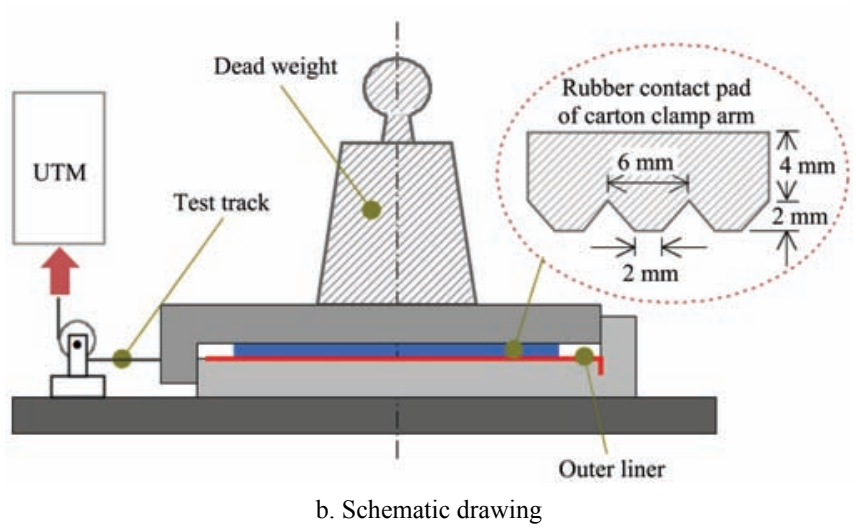

Figure 1 Static-frictional coefficient measuring system

Measurement test for the frictional force between sample materials was performed according to the ISO 15113 specification $^{[19]}$. While the plate with the rubber contact pad moves with a constant speed $(50 \mathrm{~mm} / \mathrm{min})$, 
the frictional force was continuously measured, and the direction of applied force from the UTM and the direction of frictional force were consistently maintained in order to prevent torque and stick-slip phenomena which can be possible between sample materials. The static-frictional coefficient was calculated as the ratio of the maximum frictional force to the dead weight (294 N). Five replicate tests were conducted for each test conditions. Prior to test, all specimens were pre-conditioned for $72 \mathrm{~h}$ at a standard atmosphere of $23^{\circ} \mathrm{C}$ and $50 \%$ relative humidity.

\subsection{Dynamic load factor in carton clamp handling}

In this study, a large refrigerator package (weight: $1760 \mathrm{~N}$, dimension: $\mathrm{L} \times \mathrm{W} \times \mathrm{D}=1003 \mathrm{~mm} \times 980 \mathrm{~mm} \times$ $1880 \mathrm{~mm}$ ) was selected as the target HCP. This target HCP is cushioned and supported by upper pad (density: $20 \mathrm{~kg} / \mathrm{m}^{3}$ ), side pad (density: $20 \mathrm{~kg} / \mathrm{m}^{3}$ ) and bottom base (density: $25 \mathrm{~kg} / \mathrm{m}^{3}$ ) in a corrugated paperboard container (flute type: BB, outer liner: KLB175). As shown in Figure 2, a handling test course was designed to measure the dynamic load factor by using the expected hazards during the carton clamp handling of the target HCP. The hazards in the handling test course include the carton clamp truck driving movement (forward and backward), height difference between the loading dock and the trailer, turnaround movement of the carton clamp truck and sudden stop movement after lifting the HCP up to the required height for multi-stacking.

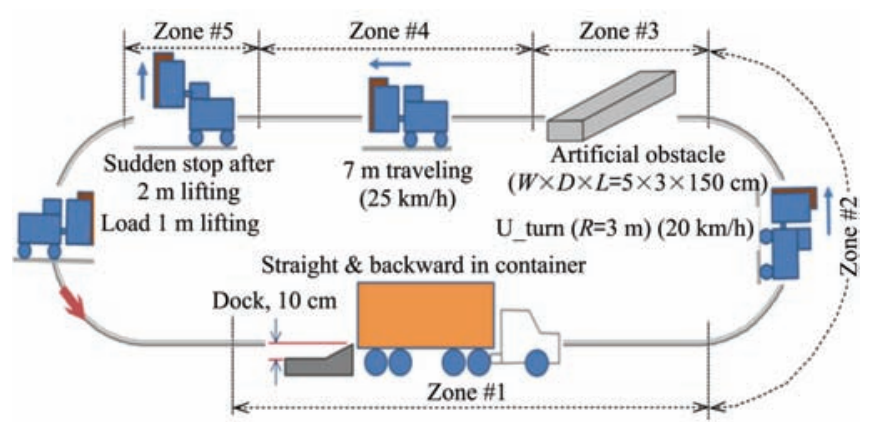

Figure 2 Handling test course designed for measuring the dynamic load factor

We used a diesel carton clamp (Model: 20D, Hyundai Heavy Industries, South Korea) with aluminum clamp arm of $1210 \mathrm{~mm} \times 1210 \mathrm{~mm}$ (area: $1.46 \mathrm{~m}^{2}$ ) for the estimation of dynamic load factor. The main body of the carton clamp did not have any device for absorbing external shock and vibration, however, a horizontal spring was built inside of both clamp arm shafts to alleviate the horizontal shock towards the loads ${ }^{[20]}$. A three-axis Integrated Circuit Piezoelectric (ICP) accelerometer (8763B100, Kistler Instrument Corp., USA) was used to collect vibration signals during handling test with $1 \mathrm{kHz}$ of sampling rate. Maximum acceleration, sensitivity and frequency response of the accelerometer are $100 \mathrm{G}$ (a multiple of acceleration due to a gravity of $9.81 \mathrm{~m} / \mathrm{s}^{2}$ ), $50 \mathrm{mV} / \mathrm{G}$ and $\max$. $5 \mathrm{kHz}$, respectively. The accelerometer was firmly attached to the top-center surface of the package. In addition, a data logger (SoMat e-DAQ, HBM GmbH, Germany) was used for the data acquisition and storage. The number of analog input, maximum sampling rate and $\mathrm{A} / \mathrm{D}$ resolution of the data logger are 16 channels, $10 \mathrm{kHz}$ and 16 bit, respectively. In addition, each handling operation was recorded by a video camera to further investigate the hazards occurred during the handling operation. Following the data collection, we performed a synchronization operation to analyze and match the recorded video clips of each handling to its corresponding vibration data as shown in Figure 3. The time-domain vibration signal in each handling operation was measured three times, and then the G-rms and the highest vibration (maximum acceleration) for each zone were analyzed. Figure 4 shows the schematics of carton clamp handling method for the target HCPs, and the handling loads for both methods were $1760 \mathrm{~N}$ and $3520 \mathrm{~N}$, respectively.

\subsection{Theoretical minimum clamping pressure}

As shown in Figure 5, a carton clamp applies pressure to the two opposite sides of the load using hydraulic power, and the resultant friction allows the clamping apparatus to lift up the load. Rubber contact pads $(300 \mathrm{~mm} \times 300 \mathrm{~mm})$ are secured to cover the whole inside surface of the clamp arms to increase the frictional force between the clamp arms and loads.

During carton clamp handling, the frictional force $(f)$ between the clamp arms and the loads should be equal or greater than the maximum dynamic load which occurred during clamp handling, as shown in Figure 6. The dynamic weight $\left(W^{\prime}\right)$ can be calculated by multiplying the weight $(W)$ of the loads with equivalent dynamic load factor $(1+d f)$ which is the measured acceleration 
(dynamic load factor expressed in G-force) of the load which was happened during a shock event. The frictional force can be calculated by multiplying the clamping force $(F)$ and the static-frictional coefficient between the contact pad of the clamp arm and the load. In this case, the clamping force can be calculated as clamping pressure multiplied by the effective contact area of the clamp arm. Accordingly, the theoretical minimum clamping pressure can be expressed in Equation (3).

$$
\begin{gathered}
W^{\prime}=(1+d f) \cdot W \\
f=F \cdot \mu \geq W^{\prime}
\end{gathered}
$$

$$
P \geq \frac{F}{2 A} \rightarrow P \geq\left(\frac{1+d f}{\mu}\right)\left(\frac{W}{2 A}\right)
$$

where, $W$ is the actual weight of the load (handling load weight), $\mathrm{N} ; W^{\prime}$ is the dynamic weight of the load, $\mathrm{N} ; d f$ is the dynamic load factor expressed in G-force (a multiple of acceleration due to gravity $\left(9.81 \mathrm{~m} / \mathrm{s}^{2}\right) ; f$ is the static-frictional force, $\mathrm{N} ; F$ is the clamping force of the carton clamp arm, $\mathrm{N} ; \mu$ is the static-frictional coefficient between the load and the contact pad of clamp arm; $P$ is the theoretical minimum clamping pressure, $\mathrm{kPa} ; A$ is the effective contact area between the clamp arm and the load, $\mathrm{m}^{2}$.
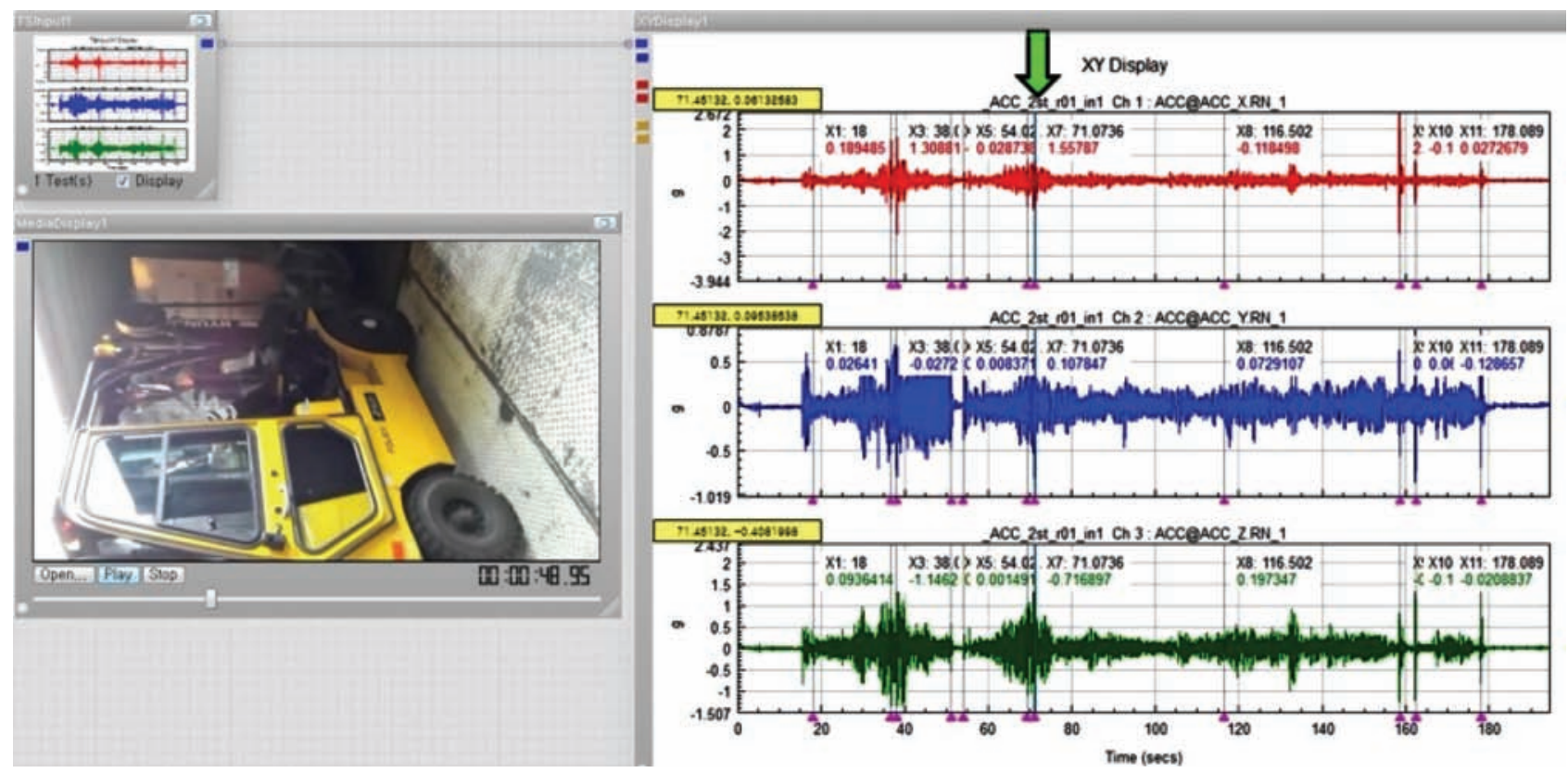

Figure 3 A representative example of vibration synchronizing process

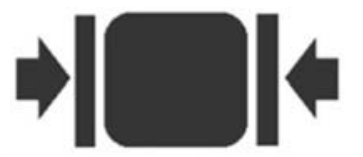

a. Single package handling

Figure 4 Schematics of carton clamp handling method for the target HCP

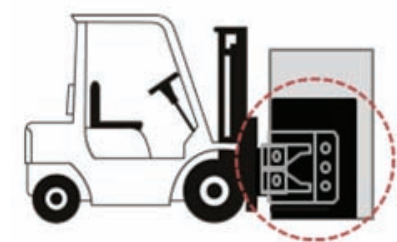

Main body of forklift truck+attachment

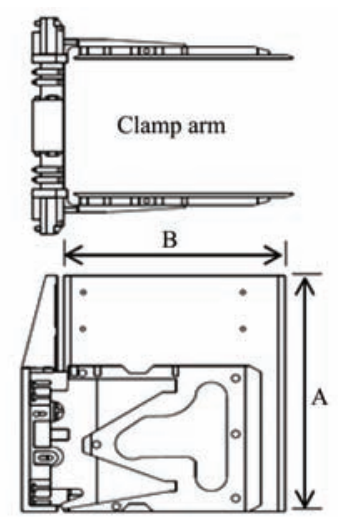

Figure 5 Schematics of carton clamp and carton clamp arm

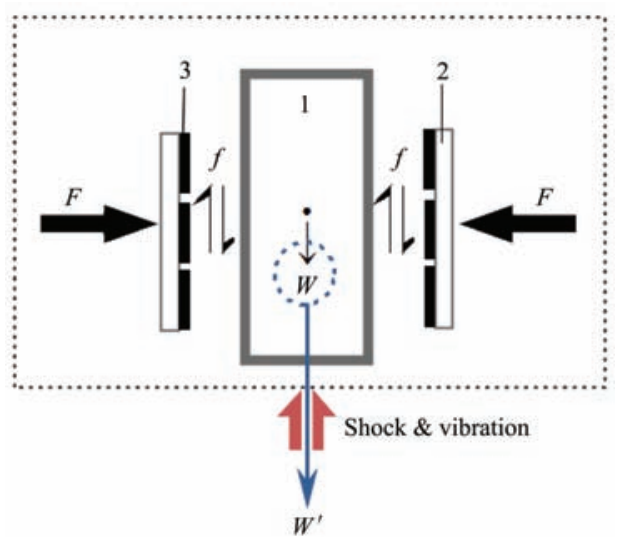

1. Packaged product 2 . Aluminum clamp arm 3. Rubber contact pad Figure 6 Illustration of frictional force during clamping operation

\subsection{Field test}

As shown in Figure 7, the slip distances of the target HCPs from the clamp arm were measured through field tests. The same diesel carton clamp was used with 
aluminum clamp arm of $1210 \mathrm{~mm} \times 1210 \mathrm{~mm}$ which used in the estimation of dynamic load factor, and the clamping pressures calculated by Equation (3) were applied to target HCPs (both single package and two packages). The weights of two HCP samples were $1760 \mathrm{~N}$ and $3520 \mathrm{~N}$, respectively.

The static-frictional coefficient between the rubber contact pad and the outer liner of HCP sample (KLB175) and the effective contact area in the field tests were 0.77 (CD) and $1.19 \mathrm{~m}^{2}(1210 \mathrm{~mm} \times 980 \mathrm{~mm})$, respectively. The slip distances between the clamp arm and the HCPs were measured at four bottom corners when the clamps were suddenly stopped after $2 \mathrm{~m}$ lifting. This operation is considered as one of the hazards during the carton clamp handling. Measurements were repeated three times for the same handling condition with three new HCP samples.

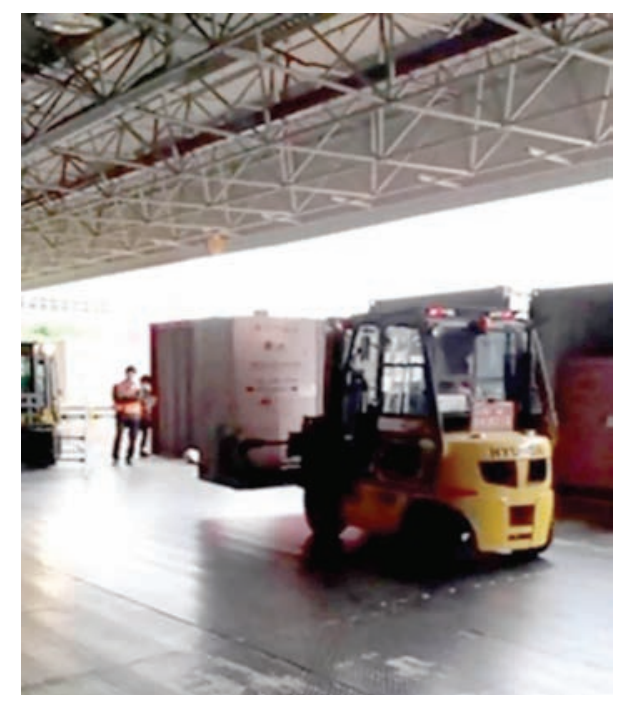

Figure 7 Measurement of slip distance of the target HCP from clamp arm through field test

\section{Results and discussion}

\subsection{Static-frictional coefficients}

The results of the static-frictional coefficient are presented in Figure 8. For all kinds of sample materials, the combination of two outer liners of KLB175 with MD shows the lowest static-frictional coefficient. In addition, when the static-frictional coefficients obtained from the combination of two outer liners are concerned in terms of fiber direction, the combination of two outer liners with MD shows the lower value. In contrast, the results with $\mathrm{CD}$ show the higher value. Moreover, when we consider the static-frictional coefficients obtained only between the outer liner and rubber contact pad, the combination of KLB175 outer liner and rubber contact pad shows the lowest value as 0.68 with MD and 0.77 with $\mathrm{CD}$, respectively. However, the results from $\mathrm{CD}$ are higher than that from MD by $5.6 \%-13.0 \%$ for this test condition.

The static-frictional coefficient obtained from the combination of outer liner and the rubber contact pad was 2.5-2.8 times higher than those obtained from the combination of two outer liners. KLB175 is known as the most commonly used outer liner of the target HCP in South Korea, and in this case, the static-frictional coefficients between the HCP and the rubber contact pad of the carton clamp arm was estimated as 0.77 for $\mathrm{CD}$ and 0.68 for MD, respectively. The values between two target HCPs were considered as 0.26 for $\mathrm{CD}$ and 0.22 for MD (Figure 8).

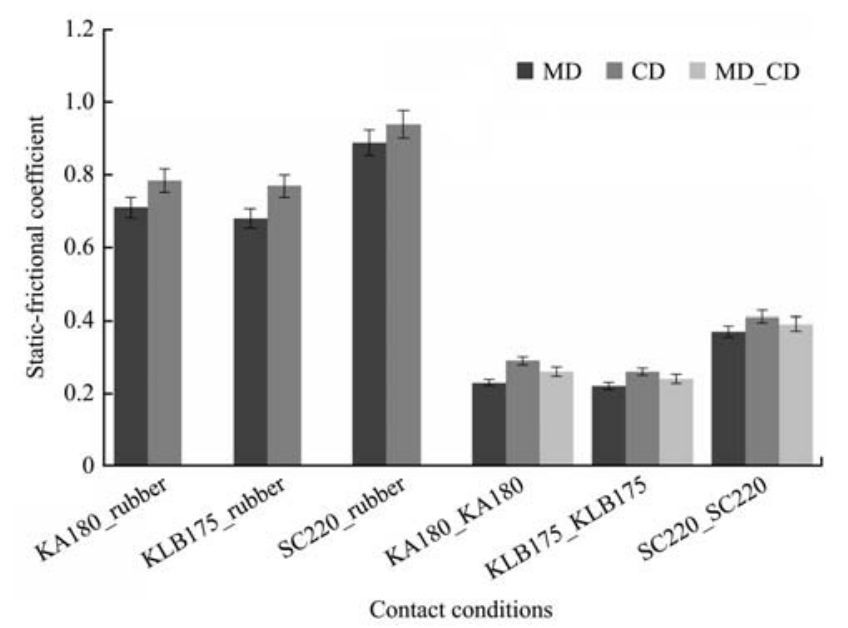

Figure 8 Analyzed static-frictional coefficients for various contact conditions

\subsection{Dynamic load factor during carton clamp handling}

Figure 9 shows a vibration data after the synchronization process for both single package handling and two packages handling operations. The G-rms and the maximum acceleration for each zone of the handling test course were described in Table 2. It shows that the G-rms for both vertical vibration ( $x$-axis) and lateral vibration (zaxis) directions are higher than G-rms for longitudinal vibration ( $y$-axis) direction which parallel to the traveling direction of clamp. Thus, the maximum acceleration representing the dynamic load factor was selected with the highest G-rms for vertical vibration $(x$-axis) direction. 


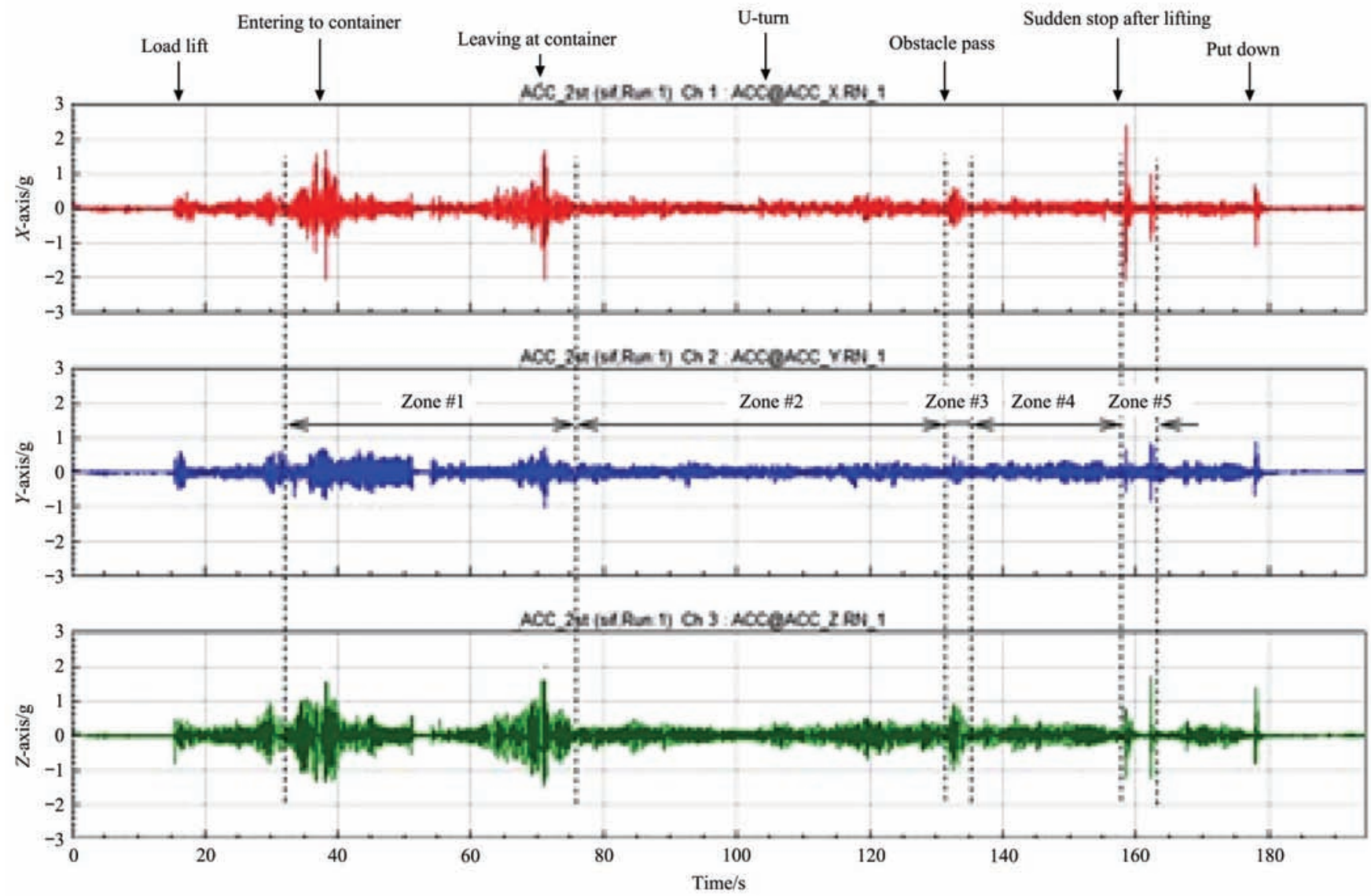

a. Single package handling

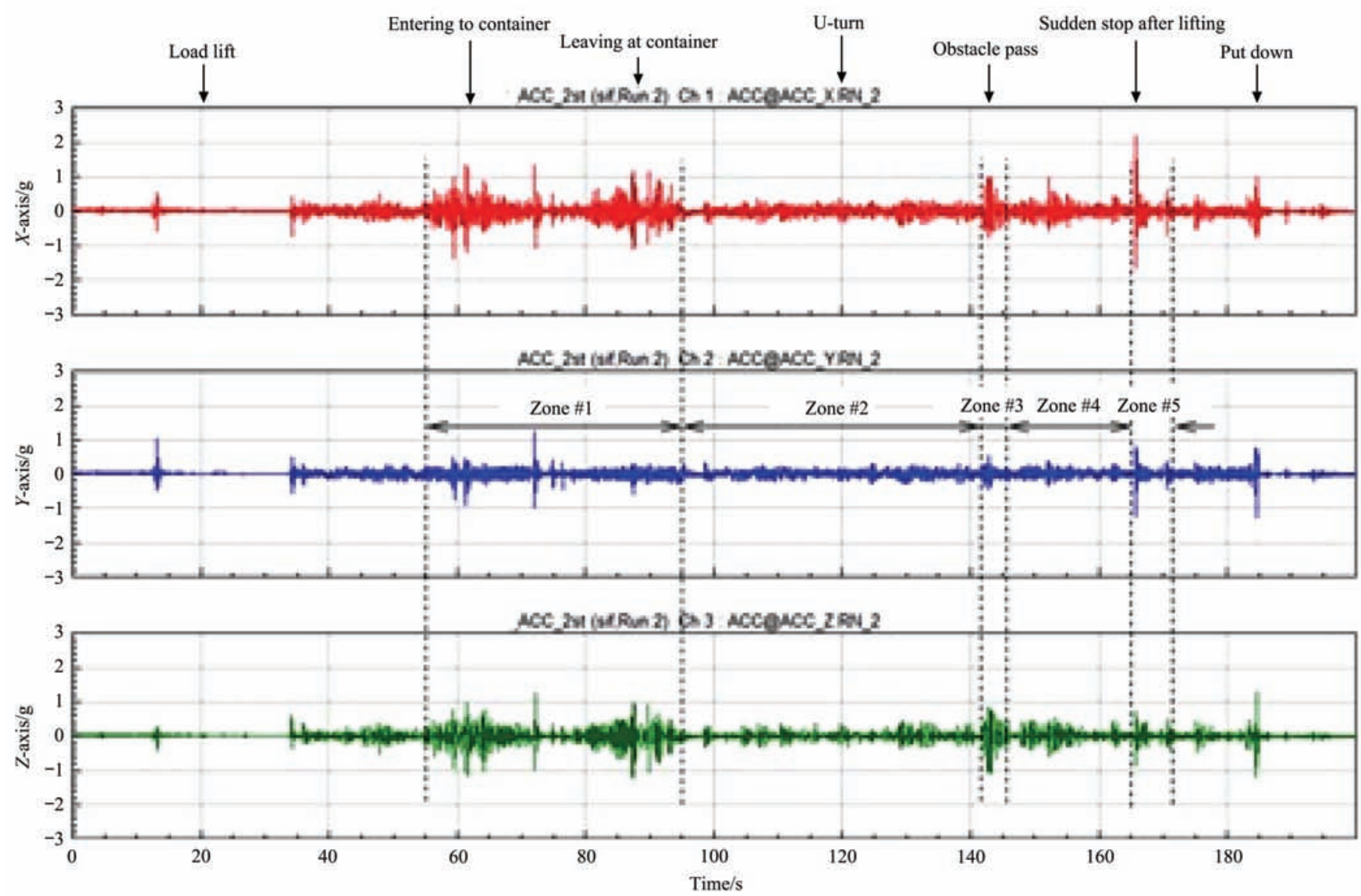

b. Two package handling

Figure 9 Vibration measurement at each zone of the handling test course for single package handling and two packages handling of the target $\mathrm{HCP}$ 
Table 2 G-rms and maximum accelerations obtained during carton clamp handling of the target $\mathrm{HCP}$

\begin{tabular}{|c|c|c|c|c|c|c|}
\hline \multirow{2}{*}{ Specification } & & \multicolumn{5}{|c|}{ Single package handling } \\
\hline & & Zone \#1 & Zone \#2 & Zone \#3 & Zone \#4 & Zone \#5 \\
\hline \multirow{3}{*}{ G-rms } & $x$ & 0.33 & 0.14 & 0.35 & 0.16 & 0.23 \\
\hline & $y$ & 0.15 & 0.09 & 0.10 & 0.10 & 0.11 \\
\hline & $z$ & 0.23 & 0.14 & 0.20 & 0.14 & 0.14 \\
\hline \multirow{3}{*}{$\begin{array}{c}\text { Max. } \\
\text { acceleration }(\mathrm{G})\end{array}$} & $x$ & 1.8 & 0.4 & 0.9 & 0.6 & 2.1 \\
\hline & $y$ & 0.7 & 0.3 & 0.4 & 0.3 & 0.8 \\
\hline & $z$ & 1.6 & 0.5 & 0.6 & 0.4 & 1.7 \\
\hline \multirow{3}{*}{$\begin{array}{l}\text { Overall } \\
\text { G-rms }\end{array}$} & $x$ & & & 0.23 & & \\
\hline & $y$ & & & 0.12 & & \\
\hline & $z$ & & & 0.18 & & \\
\hline \multirow{2}{*}{\multicolumn{2}{|c|}{ Specification }} & \multicolumn{5}{|c|}{ Two packages handling } \\
\hline & & Zone \#1 & Zone \#2 & Zone \#3 & Zone \#4 & Zone \#5 \\
\hline \multirow{3}{*}{ G-rms } & $x$ & 0.30 & 0.11 & 0.36 & 0.15 & 0.18 \\
\hline & $y$ & 0.09 & 0.06 & 0.08 & 0.06 & 0.10 \\
\hline & $z$ & 0.24 & 0.12 & 0.22 & 0.13 & 0.12 \\
\hline \multirow{3}{*}{$\begin{array}{c}\text { Max. } \\
\text { acceleration }(G)\end{array}$} & $x$ & 1.5 & 0.4 & 1.0 & 0.9 & 2.0 \\
\hline & $y$ & 0.7 & 0.3 & 0.5 & 0.4 & 0.8 \\
\hline & $z$ & 1.3 & 0.4 & 0.8 & 0.5 & 1.5 \\
\hline \multirow{3}{*}{$\begin{array}{l}\text { Overall } \\
\text { G-rms }\end{array}$} & $x$ & & & 0.18 & & \\
\hline & $y$ & & & 0.08 & & \\
\hline & $z$ & & & 0.16 & & \\
\hline
\end{tabular}

Note: All data represent the mean of three replications.

The vertical vibration can be significantly considered during the clamp handling operation, especially, when the clamp arm was suddenly stopped after lifting the HCP up to the specified height. This handling operation may induce a high acceleration which can cause the failure of clamping or unexpected slippage of products. The container's loading/unloading operations generated the second highest dynamic load factor because of the height difference between the loading dock and the container. As a result, the maximum dynamic load factor was determined as $2 \mathrm{G}$ with considering the acceleration obtained from the single and two packages handling operations in zone \#5. The similar result about dynamic load factor was observed in the previous study; the dynamic weight would be two times greater than the static weight during clamp handling for paper rolls because of the acceleration force on $\mathrm{it}^{[16]}$.

\subsection{Theoretical minimum clamping pressure}

In order to estimate the theoretical minimum clamping pressure as a function of the handling load weight and the effective contact area of the clamp arm, the lowest static-frictional coefficient between the rubber contact pad and the outer liners of $\mathrm{CD}$ and maximum dynamic load factor were substituted into Equation (3). The theoretical minimum clamping pressure was then induced as Equation (4).

$$
P=0.0026 \times\left(\frac{W}{A}\right)
$$

Based on the general contact area of the clamp arm $\left(1-2 \mathrm{~m}^{2}\right)$, the theoretical minimum clamping pressures were estimated according to the handling load weight as shown in Table 3. When the weight of the target HCP and the size of the carton clamp arm were $1760 \mathrm{~N}$ $(\mathrm{L} \times \mathrm{W} \times \mathrm{D}=1003 \mathrm{~mm} \times 980 \mathrm{~mm} \times 1880 \mathrm{~mm})$ and $1210 \mathrm{~mm} \times$ $1210 \mathrm{~mm}$ (area: $1.46 \mathrm{~m}^{2}$ ), the static-frictional coefficient between the rubber contact pad and the KLB175 outer liner and the effective contact area of the clamp arm were $0.77(\mathrm{CD})$ and $1.19 \mathrm{~m}^{2}(1210 \mathrm{~mm} \times 980 \mathrm{~mm})$, respectively. Accordingly, the theoretical minimum clamping pressure values for single package handling $(1760 \mathrm{~N})$ and two packages handling $(3520 \mathrm{~N})$ can be calculated by Equation (4) as $2.96 \mathrm{kPa}$ and $5.92 \mathrm{kPa}$, respectively.

From the results of Equation (4), we can adjust the optimal clamping pressure during the handling operation. If the calculated clamping pressure is greater than the allowable compressive strength on the product, the product can be damaged. Therefore, the handling load weight should be reduced or the clamp arms should be replaced with the larger one to increase the effective contact area.

\subsection{Field test}

Table 3 shows the slip distances of the target HCP from the clamping arm during the field test using the clamping pressures which calculated in this study. The slip distance during the two packages handling was higher than that of the single package handling, and the maximum slip distance was $3.2 \mathrm{~mm}$ at the front section of the target HCP because a heavy part (side doors, 441 $\mathrm{N}, 27 \%$ of the refrigerator weight $1617 \mathrm{~N}$ ) was positioned at the front of the target HCP. This slip distance was mainly caused by a forward tilting motion of the target HCP by the weight imbalance of packaged product and mechanical properties of the corrugated paperboard. 
Table 3 Slip distances of the target HCP from the clamp arm during field test

\begin{tabular}{cc}
\hline \multicolumn{2}{c}{ Sudden stop after $2 \mathrm{~m}$ load lifting } \\
\hline Single package handling $(1760 \mathrm{~N})$ & Two packages handling $(3520 \mathrm{~N})$ \\
\hline $2.8 \mathrm{~mm}(0.5)$ & $3.6 \mathrm{~mm}(0.8)$ \\
\hline
\end{tabular}

Note: The values in parentheses are standard deviation, and all data represent the average of three replications of the greatest deflection of the bottom corners.

During the carton clamping operation, the flutes of the corrugated paperboard in the HCP can experience shear stress which can induce the vertical displacement of the HCP. In addition, a forward tilting motion of the target HCP during field test can lead to the slippage because the center of gravity might not be in the geometrical center of the target product. These various conditions in the field test caused a vertical force, and as a result the slippage has been observed in the field test.

\section{Conclusions}

In this study, we developed a numerical model to determine the theoretical minimum clamping pressure during the carton clamp handling of the heavyweight corrugated package using the handling load weight and the effective contact area of the carton clamp arm. This model was developed using the static-frictional coefficients between the HCPs and between the HCP and the rubber contact pad of the carton clamp arm, as well as the dynamic load factor which occurred during the carton clamp handling operation. A field test was also conducted to estimate the feasibility of clamp pressures which calculated in this study. The summaries of the results are as follows:

(1) The vertical vibration resulted in the maximum accelerations during the clamp handling. The averaged dynamic factor $2 \mathrm{G}$ was estimated when the clamp arm was suddenly stopped after lifting the load up to the specified height. The container's loading/unloading operations generated the second highest dynamic load factor which might be caused by the height difference between the loading dock and the container.

(2) The static-frictional coefficients between the outer liners and between the outer liner and the rubber contact pad were the smallest for the KLB175 outer liner among the selected samples.

(3) A theoretical minimum clamping pressure in carton clamp handling for the heavyweight corrugated package was estimated as a function of the handling load weight and the effective contact area of clamp arm as follow.

$$
P(\mathrm{kPa})=0.0026 \times\left(\frac{\text { Handling Load Weight }(\mathrm{N})}{\text { Clamp Arm Contact Area }\left(\mathrm{m}^{2}\right)}\right)
$$

(4) Averaged slip distance from the single package and two packages handling was $3.2 \mathrm{~mm}$ through the field tests by using a theoretical minimum clamping pressure calculated by the developed numerical model, and we expect that the $3.2 \mathrm{~mm}$ slip distance will be acceptable for a safe operation in the handling environment.

Through this study we constructed a series of instruments and methods to estimate a carton clamping pressure for the optimization of handling of the heavyweight corrugated package. This study can provide the researchers or on-site staffs with valuable information about the instrumentations, numerical modeling and measurements of a carton clamping pressure. In conclusion, we expect that the suggested approach using numerical analysis will be quite useful for estimating the clamping pressure in carton clamps used to handle large packages or unitized agricultural product packages.

\section{Acknowledgments}

This work was supported by the Financial Supporting Project of Long-term Overseas Dispatch of Pusan National University's Tenure-track Faculty, 2014.

\section{[References]}

[1] Hellström D, Saghir M. Packaging and logistics interactions in retail supply chains. Packaging Technology and Science, 2007; 20: 197-216.

[2] Jahre M, Hattelan C J. Packages and physical distribution: implications for integration and standardization. International Journal of Physical Distribution Logistics Management, 2004; 34: 123-139.

[3] Wasala W M C B, Dharmasena D A N, Dissanayake C A K, Tilakarathne B M K S. Feasibility study on styrofoam layer cushioning for banana bulk transport in a local distribution $\mathrm{s}$ ystem. Journal of Biosystems Engineering, 2015; 40: 409-416.

[4] Chen Y X, Chen L, Wang R C, Xu X, Shen Y J, Liu Y L. 
Modeling and test on height adjustment system of electrically-controlled air suspension for agricultural vehicles. Int J Agric \& Biol Eng, 2016; 9(2): 40-47.

[5] ASAE. CIGR HANDBOOK of agricultural engineering Vol VI - Agro processing engineering, 1999.

[6] Zhong C, Saito K, Kawaguchi K. Improvement of Equivalent Drop Theory for Transport Packaging. Packaging Technology and Science, 2013; 26: 67-81.

[7] Korea Industrial Standard. KS T 0001: Glossary of terms for physical distribution. Gwacheon, Korea: Korean Agency for Technology and Standards, 2010.

[8] Saghir M. Packaging information needed for evaluation in the supply chain: the case of the Swedish grocery retail industry. Packaging Technology and Science, 2002; 15: 37-46.

[9] Cascade Corporation. Bring palletless handling to your operation. Portland, USA, 2011.

[10] Lift Technologies, Appliance and carton clamps. Westminster, South Carolina, USA. 2015.

[11] Spencer D K, Ebeling C W. Push/pull \& slipsheet handling manual. Global Solutions in Materials Handling, Cascade Corporation, 2011.

[12] Singh J, Blumer T, Roy S, Saha K. Carton clamp test methodologies and the effects on load containment and retention. Packaging Technology and Science, 2015; 28: $15-30$.
[13] Chan F T S, Chan H K, Choy K L. A systematic approach to manufacturing packaging logistics. The International Journal of Advanced Manufacturing Technology, 2006; 29: 1088-1101.

[14] American Society for Testing and Materials. ATSM D 6055-96: Standard test methods for mechanical handling of unitized loads and large shipping cases and crates. West Conshohocken, Pennsylvania, USA, 2014.

[15] International Safe Transit Association. ISTA 3B: Packaged-products for less-than-truckload LTL shipment. East Lansing, Michigan, USA, 2013.

[16] Peter M. Clamping force in paper roll handling. Gravure, August 2002, pp. 66-72

[17] Stewart J, Batt G. Clamp truck simulation in the laboratory environment. Proceedings of Dimension, Orlando, Florida, USA, 2005.

[18] Kim S I. Studies on design of corrugated fiberboard box for agricultural product. Thesis for Doctor of Philosophy in Food Engineering, Daegu University, South Korea, 2000.

[19] International Organization for Standardization. ISO 15113: Rubber-determination of frictional properties. Geneva, Switzerland, 2005.

[20] Hyundai Heavy Industries. Diesel counterbalance trucks. Ulsan, South Korea. http://www.hyundai-ce.com/Korean/ PIK/ICEPIK22 .aspx?type $=\mathrm{b} \& \operatorname{code}=\mathrm{b} 1$. Accessed on [2016-09-08] 